\title{
Sorption of Uranium(VI) and Thorium(IV) by Jordanian Bentonite
}

\author{
Fawwaz I. Khalili, Najla'a H. Salameh, and Mona M. Shaybe
}

Chemistry Department, University of Jordan, Amman 11942, Jordan

Correspondence should be addressed to Fawwaz I. Khalili; fkhalili@ju.edu.jo

Received 26 June 2012; Revised 16 August 2012; Accepted 26 August 2012

Academic Editor: Demeter Tzeli

Copyright (c) 2013 Fawwaz I. Khalili et al. This is an open access article distributed under the Creative Commons Attribution License, which permits unrestricted use, distribution, and reproduction in any medium, provided the original work is properly cited.

Purification of raw bentonite was done to remove quartz. This includes mixing the raw bentonite with water and then centrifuge it at $750 \mathrm{rpm}$; this process is repeated until white purified bentonite is obtained. XRD, XRF, FTIR, and SEM techniques will be used for the characterization of purified bentonite. The sorption behavior of purified Jordanian bentonite towards $\mathrm{UO}_{2}{ }^{2+}$ and $\mathrm{Th}^{4+}$ metal ions in aqueous solutions was studied by batch experiment as a function of $\mathrm{pH}$, contact time, temperature, and column techniques at $25.0^{\circ} \mathrm{C}$ and $\mathrm{pH}=3$. The highest rate of metal ions uptake was observed after $18 \mathrm{~h}$ of shaking, and the uptake has increased with increasing $\mathrm{pH}$ and reached a maximum at $\mathrm{pH}=3$. Bentonite has shown high metal ion uptake capacity toward uranium(VI) than thorium(IV). Sorption data were evaluated according to the pseudo- second-order reaction kinetic. Sorption isotherms were studied at temperatures $25.0^{\circ} \mathrm{C}, 35.0^{\circ} \mathrm{C}$, and $45.0^{\circ} \mathrm{C}$. The Langmuir, Freundlich, and Dubinin-Radushkevich (D-R) sorption models equations were applied and the proper constants were derived. It was found that the sorption process is enthalpy driven for uranium(VI) and thorium(IV). Recovery of uranium(VI) and thorium(IV) ions after sorption was carried out by treatment of the loaded bentonite with different concentrations of $\mathrm{HNO}_{3} 1.0 \mathrm{M}$, $0.5 \mathrm{M}, 0.1 \mathrm{M}$, and $0.01 \mathrm{M}$. The best percent recovery for uranium(VI) and thorium(IV) was obtained when $1.0 \mathrm{M} \mathrm{HNO}_{3}$ was used.

\section{Introduction}

Jordan is rich in industrial rocks and minerals. The main two areas containing bentonite deposits in Jordan are $\mathrm{Al}$ Yamaniyya and Al Azraq areas. Al Yamaniyya is located about $10 \mathrm{~km}$ south of Aqaba, while Al Azraq area is divided into two parts: Q'a Al Azraq and Ein Al Bayda areas.

Bentonite is suitable to isolate nuclear wastes and groundwater because of its low hydraulic conductivity, high swelling property, good self-sealing capacities, and so forth [1], Bentonite is also used as buffer material or backfill material according to its function and location in the nuclear waste disposal field [2].

The presence of uranium and thorium in the environment not only originates from the nuclear industry but also from other anthropogenic activities such as lignite burning in power stations, ore processing, and the use of fertilizers [3].
Uranium is enriched in the Phosphorite and Chalk Marl Units of central Jordan (Daba-Siwaqa area $60 \mathrm{~km}$ south of Amman). The area is currently under investigation by Areva Co. and huge reserves are expected. $\mathrm{UO}_{2}$ concentrations range between 140 and $2200 \mathrm{ppm}$ in central Jordan. Thorium is associated with the Dubaydib sandstone formation, southern Jordan, where the level of thorium oxide reaches $400 \mathrm{ppm}$ [4].

Wyoming montmorillonite, <2-/xm particle size, saturated with $\mathrm{Na}, \mathrm{K}, \mathrm{Mg}, \mathrm{Ca}$, and $\mathrm{Ba}$ ions, was studied with uranyl nitrate solutions in the concentration range $1-300$ ppm uranium. With constant amounts of clay and solution volume, the adsorption isotherms of uranyl ions on the clay followed Langmuir-type curves with increasing concentration of uranium. The maximum adsorption derived from linear Langmuir plots corresponds to the exchange capacity of the clay. Experiments with solutions of constant volume and 
constant ionicity, but with variable proportions of uranyl and other cations, showed that uranyl ions were strongly preferred by the clay to $\mathrm{Na}^{+}$and $\mathrm{K}^{+}$, but less strongly than $\mathrm{Mg}^{2+}, \mathrm{Ca}^{2+}$, and $\mathrm{Ba}^{2+}$ [5]. Adsorption of uranyl ions to SWy-1 montmorillonite was evaluated experimentally and the results were modeled to identify likely surface complexation reactions responsible for the removal of uranyl ions from solution. Uranyl ions were contacted with SWy-1 montmorillonite in an $\mathrm{NaClO}_{4}$ electrolyte solution at three ionic strengths $(I=0.001,0.01,0.1)$, at $\mathrm{pH} 4$ to 8.5 , in an $\mathrm{N}_{2}$ atmosphere. At low ionic strength, adsorption decreased from $95 \%$ at $\mathrm{pH} 4$ to $75 \%$ at $\mathrm{pH} 6.8$, while at higher ionic strength, adsorption increased with $\mathrm{pH}$ from initial values less than $75 \%$; adsorption edges for all ionic strengths coalesced above a $\mathrm{pH}$ of 7 . A site-binding model was applied that treated SWy-1 as an aggregate of fixed-charge sites and edge sites analogous to gibbsite and silica. The concentration of fixedcharge sites was estimated as the cation exchange capacity, and nonpreference exchange was assumed in calculating the contribution of fixed-charge sites to total uranyl ions adsorption. The concentration of edge sites was estimated by image analysis of transmission electron photomicrographs. Adsorption constants for uranyl ions binding to gibbsite and silica were determined by fitting to experimental data, and these adsorption constants were then used to simulate SWy1 adsorption results. The best simulations were obtained with an ionization model in which $\mathrm{AlOH}_{2}{ }^{+}$was the dominant aluminol surface species throughout the experimental range in $\mathrm{pH}[6]$.

Sorption interactions with SAz-1 montmorillonite of $\mathrm{U}(6+)$ is potentially important to understand the mechanisms and the mobility of $\mathrm{U}(6+)$ and other radionuclides at $\mathrm{pHs}$ typical of natural waters $(\mathrm{pH} \approx 6$ to $\approx 9$ ) through the subsurface environment. The results showed that $\mathrm{U}(6+)$ sorption on montmorillonite is a strong function of $\mathrm{pH}$, reaching a maximum at near-neutral $\mathrm{pH}(\approx 6$ to $\approx 6.5)$ and decreasing sharply towards more acidic or more alkaline conditions. At $\mathrm{pH}$ and carbonate concentrations typical of natural waters, sorption of $\mathrm{U}(6+)$ on montmorillonite can vary by four orders of magnitude and can become negligible at high $\mathrm{pH}$. A Diffuse-Layer model $(\mathrm{DLM})$ assuming aluminol $\left(>\mathrm{AlOH}^{\circ}\right)$ and silanol $\left(>\mathrm{SiOH}^{\circ}\right)$ edge sites and two $\mathrm{U}(6+)$ surface complexation reactions per site effectively simulates the complex sorption behavior observed in the $\mathrm{U}(6+)-\mathrm{H}_{2} \mathrm{O}-\mathrm{CO}_{2}$-montmorillonite system at an ionic strength of $0.1 \mathrm{M}$ and $\mathrm{pH}>3.5$ [7].

The adsorption of uranium and thorium on surfacemodified bentonite under hydrothermal conditions was studied using bentonite isolated from southern clay (USA). They found changes in the speciation of uranium(VI) and thorium(IV) ions which have been observed in exchanged clays as a function of hydrothermal conditioning and/or surface modification. There are indications of aggregation of both of these ions within the interlayer spacing of the clay [8].

The adsorption and thermodynamic behavior of uranium(VI) onto bentonite composite adsorbent, isolated from
Aegean Sea in Izmir Bay (Turky) composite adsorbent, was investigated. It was found that bentonite composite adsorbent is an economical and effective sorbent for uranium(VI) ions and the composite adsorbent exhibited excellent sorption selectivity for uranium(VI) [9]. Extended $\mathrm{X}$-ray absorption fine structure (EXAFS) spectroscopy has been used to investigate the adsorption of uranyl $\left(\mathrm{UO}_{2}{ }^{2+}\right)$ onto Wyoming montmorillonite. At low $\mathrm{pH}(\sim 4)$ and low ionic strength $\left(10^{-3} \mathrm{M}\right)$, uranyl has an EXAFS spectrum indistinguishable from the aqueous uranyl cation, indicating binding via cation exchange. At near-neutral $\mathrm{pH}(\sim 7)$ and high ionic strength $(1 \mathrm{M})$, the equatorial oxygen shell of uranyl is split, indicating inner-sphere binding to edge sites. Linear-combination fitting of the spectra of samples reacted under conditions where both types of binding are possible reveals that cation exchange at low ionic strengths on SWy-2 may be more important than predicted by past surface complexation models of $\mathrm{U}(\mathrm{VI})$ adsorption on related montmorillonites. Analysis of the binding site on the edges of montmorillonite suggests that $\mathrm{U}(\mathrm{VI})$ sorbs preferentially to $\left[\mathrm{Fe}(\mathrm{O}, \mathrm{OH})_{6}\right]$ octahedral sites over $\left[\mathrm{Al}(\mathrm{O}, \mathrm{OH})_{6}\right]$ sites [10].

The adsorption of Th(IV) on MX-80 bentonite as a function of $\mathrm{pH}$, ionic strength, Th(IV) concentration, and temperature was studied by using batch technique. The results indicated that the adsorption of Th(IV) on bentonite depended on $\mathrm{pH}$, ionic strength, and temperature. The adsorption of Th(IV) decreased with increasing temperature, indicating that the adsorption process of Th(IV) on bentonite was exothermic. The sorption isotherms were obtained at $T=$ 293 , 303, 313, and 323K and were analyzed with the Langmuir and Freundlich models, showing that the Langmuir model fitted the adsorption data better than the Freundlich model [11].

Recently, we reported the sorption of some heavy metals by Jordanian bentonite [12] and the sorption of uranium and thorium by Jordanian zeolitic tuff Tulul al-Shabba [13].

The primary objective of this study is the sorption of uranium and thorium by purified Jordanian bentonite from Al-Azraq at different $\mathrm{pH}=1.0,2.0$, and 3.0, at different temperature $25.0^{\circ} \mathrm{C}, 35.0^{\circ} \mathrm{C}$, and $45.0^{\circ} \mathrm{C}$, and different contact time. The purification of raw bentonite will be done by the removal of quartz. This includes mixing the raw bentonite with water and then centrifugation at $750 \mathrm{rpm}$, this process is repeated until white purified bentonite is obtained.

XRD, XRF, FTIR, and SEM techniques will be used for the characterization of bentonite.

The sorption properties of the bentonite toward uranium and thorium in aqueous solutions will be examined under various experimental conditions (batch and column experiment).

The data will be analyzed based on sorption models such as: Langmuir, Freundlich, and Dubinin-Radushkevich (DR) sorption isotherms. In order to determine the nature and characteristic of the sorption process, thermodynamic and kinetic functions will be determined during this work. 


\section{Methodology}

2.1. Materials and Instrumentation. All reagents used in this study were of analytical grad reagents. Th $\left(\mathrm{NO}_{3}\right)_{4} \cdot 5 \mathrm{H}_{2} \mathrm{O}$ is from Riedel DeHäen, $\mathrm{UO}_{2}\left(\mathrm{NO}_{3}\right)_{3} \cdot \mathrm{H}_{2} \mathrm{O}$, sodium perchlorate, sodium acetate, $65 \%$ Nitric acid are from Merck, 35\% Hydrochloric acid from analytical Rasayan, Arsenazo (III) Indicator from BDH Chemicals Ltd. Samples of Jordanian bentonite from Azraq were obtained from Natural Resources Authority (NRA-Amman-Jordan). These natural bentonite rocks were grounded gently using glass rod, and they were then sieved to remove particles greater than 120 mesh $(<250 \mu \mathrm{m})$. The bentonite portions of particle size less than 120 mesh were used in further purification to be used in this investigation.

Infrared spectra were recorded using a Thermonicollet Nexus 870 FTIR. The thermal gravimetric analysis (TGA) was recorded using NETZSCH STA 409 PC. The main components and minor components present in bentonite were studied by X-ray powdered diffraction (Shimadzu PXRD6000). The XRF measurements were carried out by a sequential wavelength dispersive X-Ray Fluorescence spectrometer (Shimadzu XRF-1800). Cyberscan waterproof PC 300 meter was used for $\mathrm{pH}$ measurements. The shape and surface morphology of bentonite samples were also studied with (Shimadzu-SEM SUPER SCAN SSX Series). The analytical balance that was used is Shimadzu and its type is AW120 $(0.1 \mathrm{mg})$. Shaking of samples was done using Clifton Shaker equipped with a thermostat. UV-VIS Spectrophotometer was from Spectroscan model 80DV with software UV Win5 v5.0.5.

2.2. Purification of Al-Azraq Bentonite. The main aim of this purification is to remove quartz. This process was done using the following steps: firstly, the bentonite samples of particle size less than $250 \mu \mathrm{m}$ were mixed with distilled water and then the suspension was centrifuged at $750 \mathrm{rpm}$ to obtain particles less than $2 \mu \mathrm{m}$. These particles were carefully separated in large bottles. The centrifugation was repeated for further five times [14]. The centrifuged (pure) bentonite samples were dried in an oven at $105^{\circ} \mathrm{C}$ for 4 hours and stored in polyethylene bottles.

\subsection{Spectrophotometric Procedure for Th(IV) and U(VI)}

2.3.1. Preparation of Arsenazo (III) Indicator Solution. A $0.10 \%$ aqueous solution of Arsenazo (III) (Figure 1) was used as a spectrophotometric reagent in the determination of thorium(IV) and uranium(VI) ion concentration [15].

The spectrophotometric determination of uranium(VI) and thorium(IV) ions in the aqueous solution was carried out as mentioned in our previous work [16].

\subsection{Sorption Experiments}

2.4.1. Metal Ion-Uptake by Bentonite Using Batch Sorption. Batch sorption was carried out using Pyrex glass flasks. Experiments were performed for determination of the equilibrium time for the sorption process involving $0.05 \mathrm{~g} \pm$ $0.1 \mathrm{mg}$ of the bentonite with $50.0 \mathrm{~mL}$ of metal ion solution added; the mixed solutions were mechanically shaken. The contact time was varied from 0.15 hour to 72 hours at $25^{\circ} \mathrm{C}$, the concentration of the metal ion remaining in solution was determined with UV-VIS. Similar experiments were also carried out at different $\mathrm{pH}$ 1.0, 2.0, and 3.0.

The mass of the sorbed metal per unit mass of the bentonite was calculated $[12,13]$ using the following equation:

$$
q=\left(C_{i}-C_{e}\right) \times \frac{V}{m}
$$

$q$ : metal ion uptake by bentonite in ( $\mathrm{mg} \mathrm{M} / \mathrm{g}$ bentonite), $C_{i}$ : initial metal concentration ( $\mathrm{ppm}), \mathrm{C}_{e}$ : the residual concentration of metal ion in solution at equilibrium in (ppm), and $m$ : mass of bentonite $(\mathrm{g})$. The percentage of metal ion loading by bentonite expressed as percentage uptake was calculated (2) where

$$
\% \text { Metal uptake }=\frac{C_{i}-C_{e}}{C_{i} \times 100}
$$

Distribution Coefficient $\left(K_{d}\right)$ is a standard parameter in the assessment of the physiochemical behavior of metal ion between solid and liquid phase. It can be used to evaluate the sorption and retention of the metal ion in bentonite.

$K_{d}$ is calculated using the following equation:

$$
K_{d}=\frac{\text { metal ion on the polymer }(\mathrm{mg}) \times \text { volume of the solution }(\mathrm{L})}{\text { metal ion in solution }(\mathrm{mg}) \times \text { mass of the polymer }(\mathrm{g})} .
$$

The values of $\Delta H^{*}$ and $\Delta S^{*}$ were calculated from the slopes and intercepts of the plot of $\ln K_{d}$ versus $1 / T$

$$
\ln K_{d}=\left(\frac{\Delta S^{*}}{R}\right)-\left(\frac{\Delta H^{*}}{R T}\right)
$$

This relationship assumes that $\Delta H^{*}$ is independent on $T$, where $T$ is the absolute temperature (Kelvin).
Change in Gibbs-free energy $\left(\Delta G^{*}\right)$ was calculated using the following equation:

$$
\Delta G^{*}=\Delta H^{*}-T \Delta S^{*}
$$

2.4.2. Sorption Isotherm Studies. An accurate mass of $0.05 \mathrm{~g}$ of bentonite measured to the nearest $0.1 \mathrm{mg}$ was shaken with $50.0 \mathrm{~mL}$ of metal ion solution at different concentrations, in thermostatic shaker for $24 \mathrm{~h}$ (which had been found sufficient 
<smiles>O=[As](O)c1ccccc1N=Nc1c([As](=O)(O)O)cc2cc(S(=O)(=O)O)c(N=Nc3ccccc3[W](=O)O)c(O)c2c1O</smiles>

FIGURE 1

TABLE 1: The major XRD peaks for raw bentonite.

\begin{tabular}{lcc}
\hline Mineral & $2 \theta$ & $D(\AA)$ \\
\hline & 19.89 & 4.457 \\
Montmorillonite (bentonite) $(\mathrm{M})$ & 35.36 & 2.536 \\
& 40.30 & 2.236 \\
& 61.84 & 1.499 \\
\hline \multirow{2}{*}{ Quartz (Q) } & 20.88 & 4.251 \\
& 26.67 & 3.340 \\
Anorthite & 50.18 & 1.817 \\
& 13.71 & 6.452 \\
Calcite & 21.98 & 4.041 \\
& 28.43 & 3.137 \\
\hline
\end{tabular}

to ensure equilibrium) at $25.0^{\circ} \mathrm{C}, 35.0^{\circ} \mathrm{C}$, and $45.0^{\circ} \mathrm{C}$. The sorption isotherms were studied using similar conditions at different $\mathrm{pH}=1.0,2.0$, and 3.0.

2.4.3. Metal Ion-Uptake by Bentonite Using Column Experiment. Glass column of $150 \mathrm{~mm}$ length and $10 \mathrm{~mm}$ inner diameter was used in this experiment. The column was packed with $1.00 \mathrm{~g} \pm 0.0001 \mathrm{~g}$ of bentonite; a sample volume of $50.0 \mathrm{~mL}$ containing either uranium(VI) or thorium(IV) of $2000 \mathrm{ppm}$ was passed through the column at a flow rate of $1.0 \mathrm{~mL} / 1.5 \mathrm{~min}$. The eluate was collected in a $50 \mathrm{~mL}$ volumetric flask, and concentration of the metal ion was then determined by using UV-VIS.

2.4.4. Desorption Studies. Desorption of the uranium(VI) or thorium(IV) was carried out under column condition, where bentonite was loaded with each metal ion as described. A $50.0 \mathrm{~mL}$ of the following four different concentration from the same eluting agent, $1 \mathrm{M}, 0.5 \mathrm{M}, 0.1 \mathrm{M}$ and $0.01 \mathrm{M} \mathrm{HNO}_{3}$, were used for metal ion recovery from sorbed bentonite, keeping the flow rate of elution at $1 \mathrm{~mL} / 1.5 \mathrm{~min}$. The concentration of metal ion in the eluate was collected in ten $-5 \mathrm{~mL}$ portions, and then determined by using UV-VIS.

\section{Results and Discussion}

3.1. Characterization and Analysis of Bentonite Samples. Bentonite samples were characterized using X-ray diffraction
TABLE 2: The XRF for raw bentonite and pure bentonite.

\begin{tabular}{lcc}
\hline Compound (\%) & Raw bentonite & Pure bentonite \\
\hline $\mathrm{SiO}_{2}$ & 60.86 & 45.72 \\
$\mathrm{Al}_{2} \mathrm{O}_{3}$ & 13.03 & 13.57 \\
$\mathrm{Fe}_{2} \mathrm{O}_{3}$ & 6.51 & 8.54 \\
$\mathrm{TiO}_{2}$ & 1.10 & 0.88 \\
$\mathrm{P}_{2} \mathrm{O}_{5}$ & 0.12 & 0.09 \\
$\mathrm{CaO}$ & 1.24 & 2.78 \\
$\mathrm{MgO}$ & 3.08 & 4.76 \\
$\mathrm{~K}_{2} \mathrm{O}$ & 2.98 & 3.11 \\
$\mathrm{Na}_{2} \mathrm{O}$ & 2.85 & 3.61 \\
\hline
\end{tabular}

(XRD), XRF analysis, Scanning Electron Microscope (SEM) and Fourier Transform Infrared (FTIR) spectroscopy.

3.2. The XRD Characterization. X-ray diffraction is a nondestructive analytical technique, which reveals information about crystallographic structure. This technique is widely used in the characterization of clays. The XRD patterns for raw bentonite are shown in Figure 2. The characteristic XRD peaks for the minerals in raw bentonite are presented in Table 1. Raw Jordanian bentonite consists of montmorillonite (M) as major clay mineral, whereas quartz (Q) and calcite are present as impurities. Also, anorthite is present as minor constituent.

A comparison between raw bentonite and purified bentonite is illustrated in Figure 2. This figure shows that the percent of $\mathrm{SiO}_{2}$ decreases significantly after purification process while the montmorillonite content remains unchanged; as a result, the percent of montmorillonite in purified bentonite is increased.

The XRD patterns for raw bentonite and purified bentonite (stirring with distilled water) are shown in Figure 2. Although stirring process reduces the base line due to the removal of dusts and soluble impurities, the percent of quartz and montmorillonite did not change. The major peaks in Jordanian bentonite disagree alot with those of commercial untreated bentonite from Saudi Arabia, which contains mainly montmorillonite and kaolinite [17].

3.3. XRF. The XRF analysis for Jordanian bentonite (Table 2) shows that this type of clays consists mainly for aluminum silicate, with $\mathrm{Na}$ and $\mathrm{Ca}$ as exchangeable cations, so it is considered as intermediate bentonite with moderate swelling capacity. Upon purification the percentage of $\mathrm{SiO}_{2}$ decreased due to the removal of quartz, since quartz is not the only source of $\mathrm{SiO}_{2}$ in bentonite, while the percentages of other metal oxides increased. Jordanian bentonite contains more $\mathrm{SiO}_{2}$, less $\mathrm{Al}_{2} \mathrm{O}_{3}$, less $\mathrm{Fe}_{2} \mathrm{O}_{3}$, and less $\mathrm{CaO}$ than Saudi bentonite [17].

3.4. FTIR Spectra. Bentonite was characterized by FTIR. This technique could be used to identify the major functional groups present in bentonite. From the various wave numbers of the molecular vibrations modes, a good explanation of the 
chemical structure could be obtained. As illustrated in Figure 3 , the characteristic IR band of montmorillonite appeared at $3468 \mathrm{~cm}^{-1}$. This band represents the fundamental stretching vibrations of different $-\mathrm{OH}$ groups present in $\mathrm{Mg}-\mathrm{OH}-\mathrm{Al}$, $\mathrm{Al}-\mathrm{OH}-\mathrm{Al}$, and $\mathrm{Fe}-\mathrm{OH}-\mathrm{Al}$ units in the octahedral layer [18]. The strong peak appearing at $1035 \mathrm{~cm}^{-1}$ is related to the stretching vibrations of $\mathrm{Si}-\mathrm{O}$ groups, while the bands at 533 $\mathrm{cm}^{-1}$ and $476 \mathrm{~cm}^{-1}$ are due to $\mathrm{Al}-\mathrm{O}-\mathrm{Si}$ and $\mathrm{Si}-\mathrm{O}-\mathrm{Si}$ bending vibrations, respectively [19]. The peak at $848 \mathrm{~cm}^{-1}$ is assigned to $\mathrm{O}-\mathrm{Si}-\mathrm{O}$ asymmetric stretching, while the peak at $450 \mathrm{~cm}^{-1}$ is due to $\mathrm{O}-\mathrm{Si}-\mathrm{O}$ bending mode. On the other hand, the peak at $1647 \mathrm{~cm}^{-1}$ is for $\mathrm{H}-\mathrm{O}-\mathrm{H}$ bending whereas the peak at 890 $\mathrm{cm}^{-1}$ is due to $\mathrm{OH}$ bending bounded to $\mathrm{Fe}^{3+}$ and $\mathrm{Al}^{3+}$ [19].

The comparison between raw bentonite and purified bentonite using FTIR spectra is illustrated in Figure 4.

Figure 4 gives strong indication that the aim of purification process is achieved. According to this figure, the intensity of absorbance at $1035 \mathrm{~cm}^{-1}$ peak, which relates to $\mathrm{Si}-\mathrm{O}$ groups, decreased after purification. This can be explained by the fact that the amount of $\mathrm{SiO}_{2}$ decreases after purification process.

3.5. SEM Observations. To observe the surface morphology of raw bentonite, Scanning Electron Microscope (SEM) of gold-coated samples were taken under liquid nitrogen. Figure 5 clearly illustrates the presence of cavities in the raw bentonite. The images indicate that there are abundant pores distributed on the surface. The existence of these pores would provide convenient diffusion channels for metal ions into the interior of bentonite when it is immersed with metal ions from aqueous solutions.

Scanning electron microscope is used to study bentonite shape. Figure 5 gives good indication about the purification process and the shape of bentonite crystal. It is clearly that the quartz crystals are reduced. Bentonite appears as corn flake like crystals with fluffy appearance revealing its extremely fine platy structure $[18,20]$.

3.6. Rate of Metal Ion Sorption by Bentonite. The rate of metal ions uptake by bentonite was determined at different times $(0.15,0.25,0.5,1.0,2.0,4.0,6.0,18.0,22,24,48$ and $72 \mathrm{~h})$, with a concentration of $50 \mathrm{ppm}$ at $25^{\circ} \mathrm{C}$ to find the effect of time of the percentage of uptake other experiments were also conducted varying the $\mathrm{pH}$ values (1.0, 2.0, and 3.0). The results are of these experiments are shown in plots are shown in Figures 6 and 7.

It can be noticed from Figures 6 and 7, that saturation takes place after $6 \mathrm{~h}$, because of this we choose $24 \mathrm{~h}$ to be sure that we have reached equilibrium since it is a slow one. Also the \% uptake increased as the $\mathrm{pH}$ increased, which is due to the increase on the surface negative charge or decrease in its positive charge. The idea for using low acidic $\mathrm{pH}$ is to avoid hydrolysis of thorium(IV) and uranium(VI) ions and to simulate the removal or purification of both from their ores.

3.7. Kinetics of Sorption. Sorption kinetics is used in order to explain the sorption mechanism and sorption characteristics.

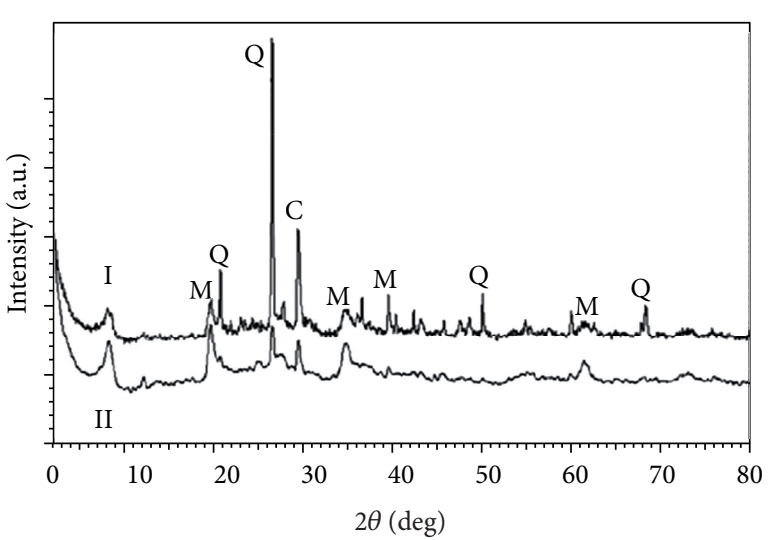

FIGURE 2: XRD patterns for (I) raw bentonite and (II) purified bentonite, M: montmorillonite, Q: Quartz, and C: calcite.

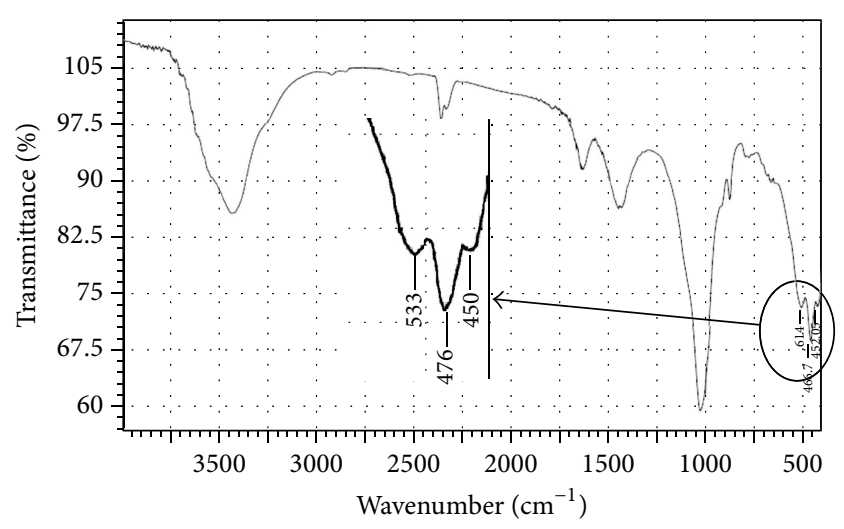

FIGURE 3: FTIR spectrum for raw bentonite.

3.8. Pseudo-First-Order Reaction Kinetic. Pseudo-first-order reaction kinetic data were calculated using the following equation:

$$
\ln \left(q_{e}-q_{t}\right)=\ln q_{e}-k_{1} t
$$

where $k_{1}$ is the rate constant for the first-order sorption, $q_{t}$ is the amount of heavy metal sorbed at time $t(\mathrm{mg} / \mathrm{g})$, and $q_{e}$ is the amount of heavy metal sorbed at saturation $(\mathrm{mg} / \mathrm{g})$. Rate constants $\left(k_{1}\right)$ were calculated from the slopes of the curves (Tables 3 and 4).

3.9. Pseudo-Second-Order Reaction Kinetic. Sorption data was also evaluated according to the pseudo-second-order reaction kinetic proposed by following equation:

$$
\frac{t}{q_{t}}=\frac{1}{\left(k_{2} q_{e}^{2}\right)}+\frac{t}{q_{e}}
$$

The plot of $t / q_{t}$ against time for each metal ion gives a linear relationship, where the values of $q_{e}$ and $k_{2} q_{e}{ }^{2}$ are obtained from the slope and intercept of $t / q_{t}$ against time plots (Tables 3 and 4$)$. 


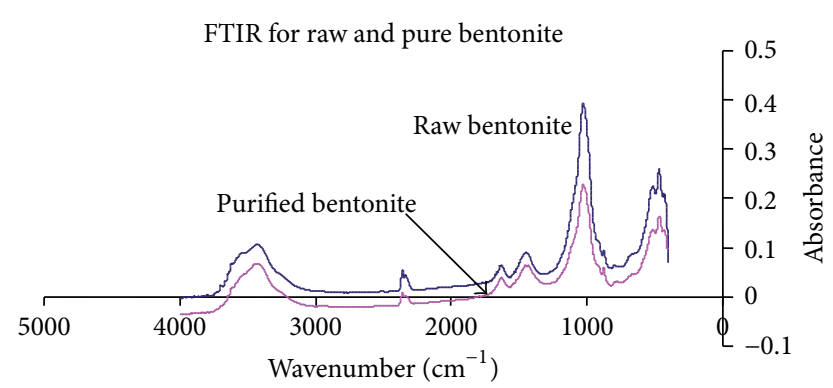

FIGURE 4: FTIR for raw and purified bentonite.

As the difference between calculated and experimental $q_{e}$ values is considered, it is seen that the removal of thorium(IV) and uranium(VI) with bentonite is well described by the second-order reaction kinetic. Moreover, all the correlation coefficients of second-order reaction kinetic are higher than that of the first-order reaction kinetic $[17,21]$.

3.10. Metal Sorption Studies on Bentonite. The sorption of thorium(IV) and uranium(VI) on bentonite were studied in order to determine the effect of concentration variation from 10 to $100 \mathrm{ppm}$ and $\mathrm{pH}$ on the isotherms of uranium(VI) and thorium(IV). The sorption isotherms were determined for thorium(IV) and uranium(VI) at different $\mathrm{pH}$ values $(1.0,2.0$, and 3.0$)$ and different temperatures $\left(25^{\circ} \mathrm{C}, 35^{\circ} \mathrm{C}\right.$, and $45^{\circ} \mathrm{C}$ ). The following linearized Langmuir, Freundlich isotherm forms, analyzed the sorption isotherms results

$$
\text { Langmuir isotherm: } \frac{c}{q}=\frac{1}{\left(q_{m} K_{L}\right)}+\left(\frac{1}{q_{m}}\right) c \text {, }
$$

Freundlich isotherm: $\log q=\log K_{F}+\left(\frac{1}{n}\right) \log c$.

Therefore, a plot of $c / q$ versus $c$ gives a straight line of slope $\left(1 / q_{m}\right)$ and intercept $1 /\left(q_{m} K_{L}\right)$, a plot of $\log q$ versus $\log c$ gives a straight line with a slope $1 / n$ and intercept $\log K_{F}$. Where $K_{L}$ parameter is related to the strength of the sorbed ion adsorbent binding (i.e., Thorium(IV) ions-bentonite), $q_{m}$ is the saturation sorption capacity, $K_{F}$ is a parameter related to the sorption capacity, and $\mathrm{n}$ is a measure of the sorption intensity $[22,23]$.

The estimated parameters of the sorption isotherms, calculated from the intercepts and slopes of the corresponding linear plots of linearized Langmuir and Freundlich for Thorium(IV) and Uranium(VI), sorption onto bentonite at different temperatures, together with their correlation coefficients $\left(R^{2}\right)$, are given in Tables 5 and 6 at different $\mathrm{pH}$ values (1.0, 2.0, and 3.0). Example plots are shown in Figures 8 and 9.

In case of Langmuir, some deviation from linearity is shown; the proposed explanation of this deviation is that when all of the available monolayer sites are saturated, some fresh internal sites can be created. The creation of the additional surface arises from the pressure of metal ions being forced into the macropore and micropore structures [24].
Since the $R^{2}$ values for Freundlich and Langmuir models are above 0.95 , the surface of bentonite is a mixture of homogeneous and heterogeneous sites and this agrees very well with SEM results.

In Freundlich isotherm, the value of $n$ denotes the type of sorption whether it is favorable or not. A value of $n$ ranging from 2 to 10 is considered favorable, a value ranging from 1 to 2 is considered moderately difficult, while a value of 0.5 or less indicates very poor sorption [25]. Therefore, based on the $n$ values from Tables 5 and 6 , sorption of thorium and uranium are moderately difficult. Based on the values of $q_{m}$ in Tables 5 and 6 , sorption of thorium(IV) is greater than uranium(VI) metal ions on bentonite.

This observation can be explained in terms of the following three factors.

(1) Hydration Energy. The adsorptivity of metal ions $\left(q_{m}\right)$ on bentonite was found to be directly proportional to the ionic radius. This is due to the decrease in enthalpy hydration $\left(-\Delta H_{h}\right)$ as the ionic radius increases [26]. Increasing the hydration energy due to increase in the hydration shell makes it more difficult for metal ion to discharge the water of hydration. The formation of aqua complex $\left[\mathrm{M}\left(\mathrm{OH}_{2}\right)_{m}\right]^{n+}$ takes place (where $m$ is larger than six, perhaps eight or nine), the aqua complex, having $m \mathrm{H}_{2} \mathrm{O}$ molecules surrounding the central ion, has a definite structure, and the cloud of water molecules (hydration shell) has another geometry than the rest of the water. Thus, when say $\mathrm{M}\left(\mathrm{NO}_{3}\right)_{n}$ salt is dissolved in water, there will be very little attraction between $\left[\mathrm{M}\left(\mathrm{OH}_{2}\right)_{m}\right]^{n+}$ and the solvated $\mathrm{NO}_{3}{ }^{-}$ion. Unless the other ions or ligands have a strong structure breaking influence, the sheath of water molecule will protect the metals ions from the influence of other anions or ligands. When complexes are formed, the approach of a ligand will interfere with the hydration shell and the ordered geometry will break down [27]. A stronger hydration shell will surround small metal ion, which has smaller radius than the metal ion with larger radius; the adsorptivity of ion of large radius is larger than small radius.

When it depends on the charge-to-size ratio, a large ratio results in an increase in hydration energy, which means that the hydrated ion prefers the solution phase, where it may satisfy its hydration requirements. Ions with lower hydration energy prefer the bentonite phase. Table 7 shows that thorium has lower hydration energy than uranium. This means that thorium can exchange easily at the bentonite surface.

(2) Hydrolysis Reaction. Hydrolysis reaction can be represented by a hydrolysis constant $\left(K_{h}\right)$

$$
\mathrm{M}^{2+}+\mathrm{H}_{2} \mathrm{O} \longrightarrow \mathrm{MOH}^{+}+\mathrm{H}^{+}
$$

From the value of $K_{h}$ in Table 5, the following sequence was observed:

$$
p K_{h}: \mathrm{UO}_{2}^{2+}>\mathrm{Th}_{4+}
$$

This indicates that at lower $p K_{h}$ value the metal ion can diffuse easily and has a stronger binding strength at bentonite surface. Thorium(IV) has a lower $p K_{h}$, so a lower resistance to reach the active sites. 


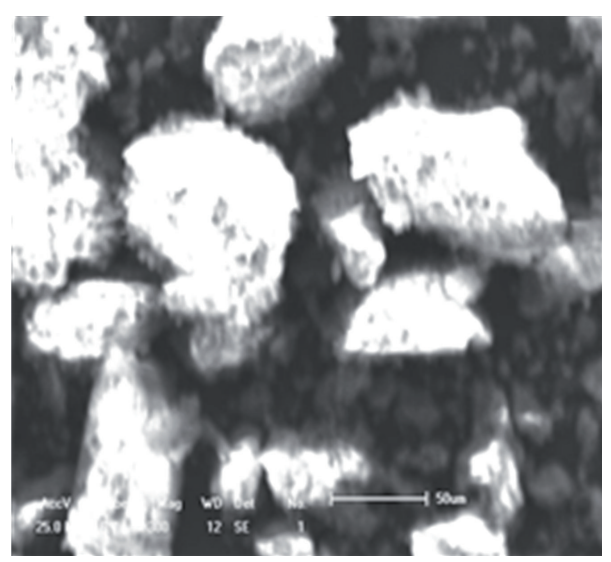

(a) Raw bentonite

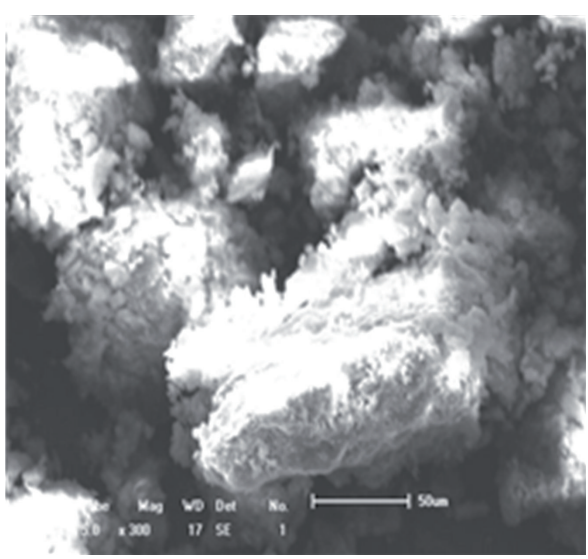

(b) Purified bentonite

Figure 5: The SEM images for Raw bentonite and Purified bentonite. Magnification $=300$ times.

TABLE 3: Comparison of sorption rate constants, experimental and calculated $q_{e}$ values for the pseudo-first- and -second-order reaction kinetics of removal for thorium(IV) by bentonite.

\begin{tabular}{lcccccccc}
\hline & \multicolumn{3}{c}{ First order } & \multicolumn{3}{c}{ Second order } \\
$\mathrm{pH}$ & $R^{2}$ & $k_{1}$ & $\ln q_{e}$ & $q_{e}$ & $R^{2}$ & $q_{e}$ & $k_{2}$ \\
\hline 1 & 0.957 & 0.0027 & 3.3221 & 27.718 & 0.995 & 35.088 & $1.977 e-4$ & 32.964 \\
2 & 0.961 & 0.0029 & 3.4685 & 32.089 & 0.994 & 43.290 & $2.001 e-4$ \\
3 & 0.937 & 0.0024 & 3.4405 & 31.203 & 0.991 & 44.248 & $2.176 e-4$ & 41.000 \\
\hline
\end{tabular}

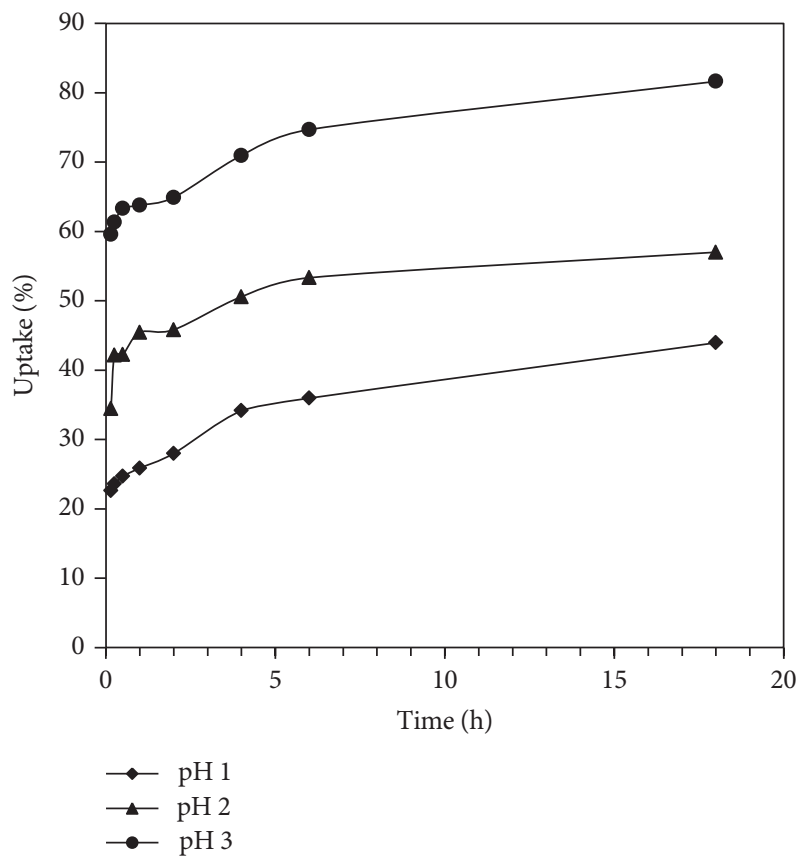

FIGURE 6: Uranium(VI) percentage uptake by bentonite at $\mathrm{pH} 1.0$, 2.0 and 3.0 at $25^{\circ} \mathrm{C}$ and concentration $50 \mathrm{ppm}$.

(3) Deprotonating the $\mathrm{SiOH}$ and $\mathrm{AlOH}$ Groups. As the $\mathrm{pH}$ increase, the amount of deprotonated $\mathrm{SiOH}$ and $\mathrm{AlOH}$ groups increases, so the negative charge on the surface and edge sites increases. This will increase the interaction between the metal ions and the bentonite (Tables 5 and 6). The higher the metal charge causes a stronger interaction. This agrees very well with previous studies $[5,6,11]$.

The correlation coefficient is a mathematical expression, which reveals the favorability of the sorption process, since the values of $R^{2}$ for Langmuir isotherm and Freundlich are very good.

As mentioned before, the maximum sorption capacity $\left(q_{m}\right)$ is determined form Langmuir sorption isotherm. In bentonite, the metal ions seem to reach saturation which means that the metal ion had filled the possible available sites, so the sorption efficiency increases to a certain level and then remained constant with concentration.

3.11. Dubinin-Radushkevich. The linear form for DubininRadushkevich (D-R) isotherm has the following expression:

$$
\begin{gathered}
\ln q=\ln q_{\max }-\beta \varepsilon^{2}, \\
\varepsilon=R T \ln \left(1+\frac{1}{C_{\mathrm{eq}}}\right),
\end{gathered}
$$

where $R$ is the ideal gas constant $\left(8.3145 \mathrm{~J} \cdot \mathrm{mol}^{-1} \cdot \mathrm{K}^{-1}\right)$ and $T$ is the absolute temperature (Kelvin). The values of $\beta$ and $q_{\max }$ are evaluated from the slope and intercept of the linear plot of $\operatorname{lnq}$ versus $\varepsilon^{2}$, where $q_{\max }$ is related to the sorption capacity and $\beta$ is the constant related to the sorption energy. 
TABLE 4: Comparison of sorption rate constants, experimental, and calculated $q_{e}$ values for the pseudo- first- and second-order reaction kinetics of removal for uranium (VI) by bentonite.

\begin{tabular}{lcccccccc}
\hline $\begin{array}{l}\text { First order } \\
\mathrm{pH}\end{array}$ & $R^{2}$ & $k_{1}$ & $\ln q_{e}$ & $q_{e}$ & $R^{2}$ & $q_{e}$ & $k_{2}$ \\
\hline 1 & 0.938 & 0.0024 & 2.5637 & 12.984 & 0.996 & 23.810 & $6.976 e-4$ \\
2 & 0.948 & 0.0019 & 2.2241 & 9.245 & 0.999 & 29.674 & $0.134 e-4$ \\
3 & 0.968 & 0.0019 & 2.5257 & 12.500 & 0.999 & 42.373 & $9.255 e-4$ & 30.076 \\
\hline
\end{tabular}

TABLE 5: The $K_{d}, n, K_{F}, R^{2}, K_{L}$, and $q_{m}$ values obtained from Langmuir and Freundlich plots for Thorium(IV).

\begin{tabular}{|c|c|c|c|c|c|c|c|}
\hline & & ndlich $n$ & & & muir model & & $T\left({ }^{\circ} \mathrm{C}\right)$ \\
\hline$C_{i}=100 \mathrm{ppm}$ & $n$ & $K_{F}$ & $R^{2}$ & $K_{L}(\mathrm{~L} / \mathrm{mg})$ & $q_{m}(\mathrm{mg} / \mathrm{g})$ & $R^{2}$ & \\
\hline 0.504 & 2.133 & 5.384 & 0.958 & 0.082 & 40.161 & 0.995 & $\begin{array}{c}\mathrm{pH}=1.0 \\
25\end{array}$ \\
\hline 0.440 & 2.099 & 4.338 & 0.979 & 0.063 & 36.631 & 0.994 & 35 \\
\hline 0.399 & 2.100 & 3.762 & 0.995 & 0.047 & 35.971 & 0.968 & 45 \\
\hline 1.881 & 1.502 & 7.271 & 0.963 & 0.066 & 95.238 & 0.989 & $\begin{array}{c}\mathrm{pH}=2.0 \\
25\end{array}$ \\
\hline 1.703 & 1.476 & 6.561 & 0.975 & 0.058 & 95.238 & 0.976 & 35 \\
\hline 1.541 & 1.437 & 5.299 & 0.992 & 0.043 & 101.01 & 0.983 & 45 \\
\hline 4.138 & 1.606 & 12.526 & 0.997 & 0.112 & 108.696 & 0.951 & $\begin{array}{c}\mathrm{pH}=3.0 \\
25\end{array}$ \\
\hline 3.811 & 1.437 & 11.153 & 0.984 & 0.090 & 123.457 & 0.981 & 35 \\
\hline 3.636 & 1.352 & 9.513 & 0.982 & 0.069 & 135.135 & 0.982 & 45 \\
\hline
\end{tabular}

The sorption-free energy $(E)$ is defined as the free energy change required for transferring one mole of ions from solution to solid surface; this energy is calculated as following:

$$
E=\frac{1}{(2 \beta)^{-0.5}} .
$$

The value of $E$ gives information about the physical and chemical features of the sorption. Low values of sorption energy $(E)$ show that the sorption has a physical nature.

The results of the Dubinin-Radushkevich concentration variation isotherms of Thorium(IV) and Uranium(VI) are shown in Table 8 . The D-R isotherm model is more general than Langmuir isotherm as it rejects the homogenous surface or constant sorption potential. As illustrated in Table 8, the values of $E$ are less than $8.00 \mathrm{~kJ} / \mathrm{mol}$, this indicates that physical forces affect the sorption [28]. It is interesting to note that the difference of $q_{\max }$ derived from the Langmuir and $q_{m}{ }^{\prime}$ derived from D-R models is quite large. The difference may be attributed to the different definition of $q_{\max }$ in the two models. In Langmuir model, $q_{\max }$ represents the maximum sorption of metal ions at monolayer coverage, whereas in D$\mathrm{R}$ model it represents the maximum sorption of metal ions at the total specific micropore volume of the sorbent. Thereby, the value of $q_{\max }$ derived from D-R model is lower than that derived from Langmuir model [29]. The values of $\beta, q_{m}{ }^{\prime}$, and $E$ for thorium(IV) and uranium(VI) are summarized in Table 8 .

3.12. Thermodynamics of Sorption on Bentonite. In order to understand the possible sorption mechanism involved in the removal process, thermodynamic functions for the system, including changes in Gibbs-free energy $\left(\Delta G^{*}\right)$, change in enthalpy of sorption $\left(\Delta H^{*}\right)$, and changes in entropy of sorption $\left(\Delta S^{*}\right)$, were calculated using the following equation:

$$
\ln K_{d}=\frac{\Delta S^{*}}{R}-\frac{\Delta H^{*}}{R T}
$$

where $K_{d}$ is the equilibrium constant, $R$ is the gas constant, and $T$ is the temperature in Kelvin.

The plot of $\ln K_{d}$ against 1/T for each metal ion (Figures 10 and 11) gives a linear relationship, where the values of enthalpy $\left(\Delta H^{*}\right)$ and entropy $\left(\Delta S^{*}\right)$ are obtained from the slope and intercept of $\ln K_{d}$ versus $1 / T$ plots. $\Delta G^{*}$ was calculated at each temperature using the following equation:

$$
\Delta G^{*}=\Delta H^{*}-T \Delta S^{*} \text {. }
$$

From the Vant Hoff equation $\Delta H^{*}$, and $\Delta S^{*}$ were calculated for $\mathrm{Th}(\mathrm{IV})$ and $\mathrm{U}(\mathrm{VI})$ as shown in Table 9. The adsorptive process is enthalpy driven for thorium(IV) and uranium(VI). The negative values of enthalpy show that the sorption of thorium(IV) and uranium(VI). on bentonite is an exothermic process. This exothermic effect can be explained by the forces of interaction between the bentonite and metal, which are stronger than those existing in both bentonite and metal alone, which means that it would prefer the product than reactant [30]. The almost zero values of $\Delta S^{*}$ suggests that the entropy of the system is decreased or stayed constant. On the other hand, these almost zero values of entropy indicate that the sorption process is irreversible and favors the stability of 
TABLE 6: The $K_{d}, n, K_{F}, R^{2}, K_{L}$ and $q_{m}$ values obtained from Langmuir and Freundlich plots for Uranium(VI).

\begin{tabular}{|c|c|c|c|c|c|c|c|}
\hline$K_{d}$ & & adlich & & & muir model & & \\
\hline$C_{i}=100 \mathrm{ppm}$ & $n$ & $K_{F}$ & $R^{2}$ & $K_{L}(\mathrm{~L} / \mathrm{mg})$ & $q_{m}(\mathrm{mg} / \mathrm{g})$ & $R^{2}$ & $T(\mathrm{C})$ \\
\hline 0.179 & 1.604 & 0.982 & 0.995 & 0.021 & 22.989 & 0.988 & $\begin{array}{c}\mathrm{pH}=1.0 \\
25\end{array}$ \\
\hline 0.149 & 1.787 & 1.126 & 0.980 & 0.028 & 17.986 & 0.970 & 35 \\
\hline 0.141 & 1.714 & 0.931 & 0.992 & 0.023 & 17.825 & 0.960 & 45 \\
\hline 0.411 & 1.865 & 2.860 & 0.990 & 0.036 & 37.594 & 0.943 & $\begin{array}{c}\mathrm{pH}=2.0 \\
25\end{array}$ \\
\hline 0.354 & 1.655 & 1.912 & 0.998 & 0.024 & 38.760 & 0.952 & 35 \\
\hline 0.339 & 1.592 & 1.706 & 0.999 & 0.022 & 39.216 & 0.973 & 45 \\
\hline 0.652 & 1.517 & 2.643 & 0.998 & 0.026 & 62.118 & 0.964 & $\begin{array}{c}\mathrm{pH}=3.0 \\
25\end{array}$ \\
\hline 0.596 & 1.572 & 2.919 & 0.985 & 0.032 & 55.866 & 0.988 & 35 \\
\hline 0.568 & 1.579 & 2.889 & 0.976 & 0.033 & 53.476 & 0.994 & 45 \\
\hline
\end{tabular}

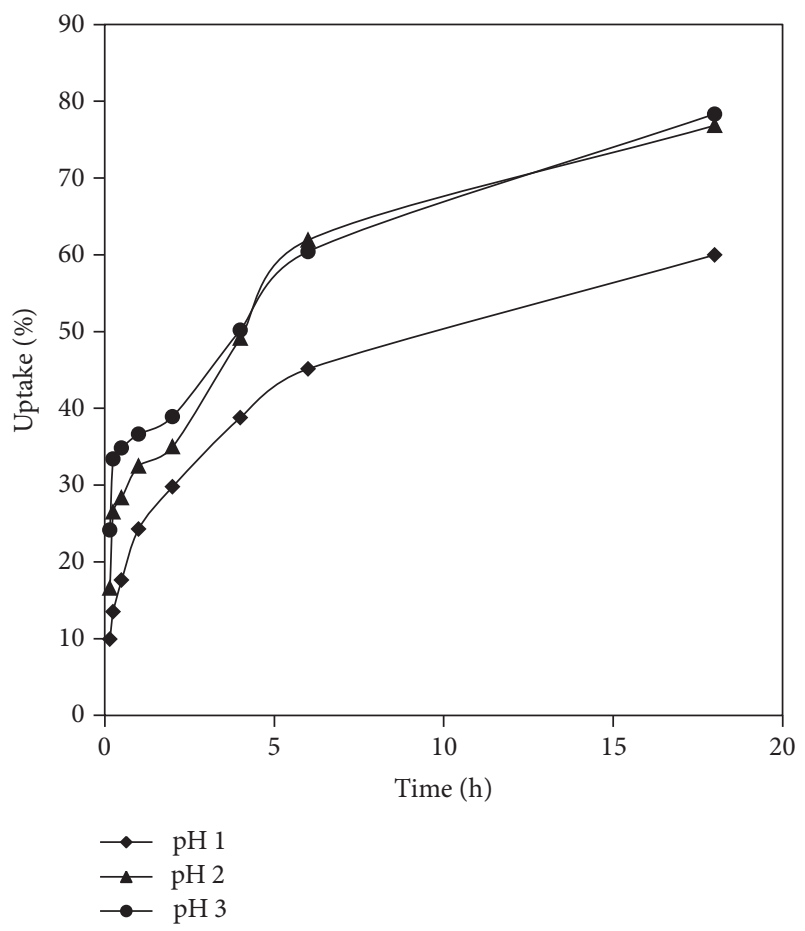

FIGURE 7: Thorium(IV) percentage uptake by bentonite at $\mathrm{pH}$ 1.0, 2.0 and 3.0 at $25^{\circ} \mathrm{C}$ and concentration $50 \mathrm{ppm}$.

TABLE 7: Chemical properties of Thorium(IV) and Uranium(VI).

\begin{tabular}{lcl}
\hline $\mathrm{U}(\mathrm{VI})$ & Th(IV) & Metals \\
\hline 0.97 & 1.19 & Ionic radius $(\AA)$ \\
4.69 & 4.00 & Hydrolysis constant at $0.1 \mathrm{M} \mathrm{NaClO}_{4}\left(p K_{h}\right)$ \\
-3958 & -3332 & Hydration energy $(\mathrm{kJ} / \mathrm{mol})$ \\
\hline
\end{tabular}

sorption. During the sorption process, the metal ions become associated with the surface of the bentonite resulting in the loss of a degree of freedom while releasing water of hydration increases the value of this function in a more or less equal
TABLE 8: Dubinin-Radushkevich (D-R) isotherm parameters for Thorium(IV) and Uranium(VI) at $\mathrm{pH}=1.0,2.0$, and 3.0 at $T=25^{\circ} \mathrm{C}$.

\begin{tabular}{lllll}
\hline $\mathrm{pH}$ & $R^{2}$ & $\beta\left(\mathrm{mol}^{2} / \mathrm{kJ}^{2}\right)$ & $q_{m}{ }^{\prime}(\mathrm{mg} / \mathrm{g})$ & $E(\mathrm{~kJ} / \mathrm{mol})$ \\
\hline 1 & 0.901 & 1.816 & 20.884 & 0.525 \\
2 & 0.859 & 0.985 & 31.785 & 0.712 \\
3 & 0.844 & 0.261 & 32.201 & 1.384 \\
\hline \multicolumn{5}{c}{ Uranium(VI) } \\
\hline 1 & 0.874 & 9.573 & 8.593 & 0.229 \\
2 & 0.842 & 3.511 & 15.120 & 0.377 \\
3 & 0.867 & 3.283 & 17.708 & 0.390 \\
\hline
\end{tabular}

TABLE 9: Thermodynamic functions for Thorium(IV) and Ura$\operatorname{nium}(\mathrm{VI})$.

\begin{tabular}{lcccc}
\hline Metal ion & $\mathrm{pH}$ & $\begin{array}{c}\Delta S^{*} \\
(\mathrm{~kJ} / \mathrm{mol} \cdot \mathrm{K})\end{array}$ & $\begin{array}{c}\Delta H^{*} \\
(\mathrm{~kJ} / \mathrm{mol})\end{array}$ & $\begin{array}{c}\Delta G^{*} \\
(\mathrm{~kJ} / \mathrm{mol}) 298(\mathrm{~K})\end{array}$ \\
\hline \multirow{3}{*}{$\mathrm{Th}(\mathrm{IV})$} & 1 & -0.027 & -6.355 & 1.691 \\
& 2 & -0.009 & -4.086 & -1.404 \\
& 3 & -0.0003 & -3.551 & -3.462 \\
\hline \multirow{3}{*}{$\mathrm{U}(\mathrm{VI})$} & 1 & -0.037 & -6.753 & 4.273 \\
& 2 & -0.026 & -5.529 & 2.219 \\
& 3 & -0.017 & -3.813 & 1.253 \\
\hline
\end{tabular}

TABLE 10: Metal ion uptake using column experiment at $\mathrm{pH}=3$, $25^{\circ} \mathrm{C}$.

\begin{tabular}{lcccc}
\hline Metal ion (II) & $\begin{array}{c}C_{i} \\
(\mathrm{ppm})\end{array}$ & $\begin{array}{c}\text { Final } \\
\text { concentration } \\
(\mathrm{ppm})\end{array}$ & $\begin{array}{c}\text { Loaded } \\
\text { concentration } \\
(\mathrm{ppm})\end{array}$ & \% Uptake \\
\hline Thorium(IV) & 2000 & 445.5 & 1554.5 & 77.7 \\
Uranium(VI) & 2000 & 481.4 & 1518.6 & 75.9 \\
\hline
\end{tabular}

value [29]. The low to negative values for $\Delta G^{*}$ indicate that the sorption process is more energy favorable at higher $\mathrm{pH}$ values, since we are talking about a heterogeneous and not a homogeneous system. 


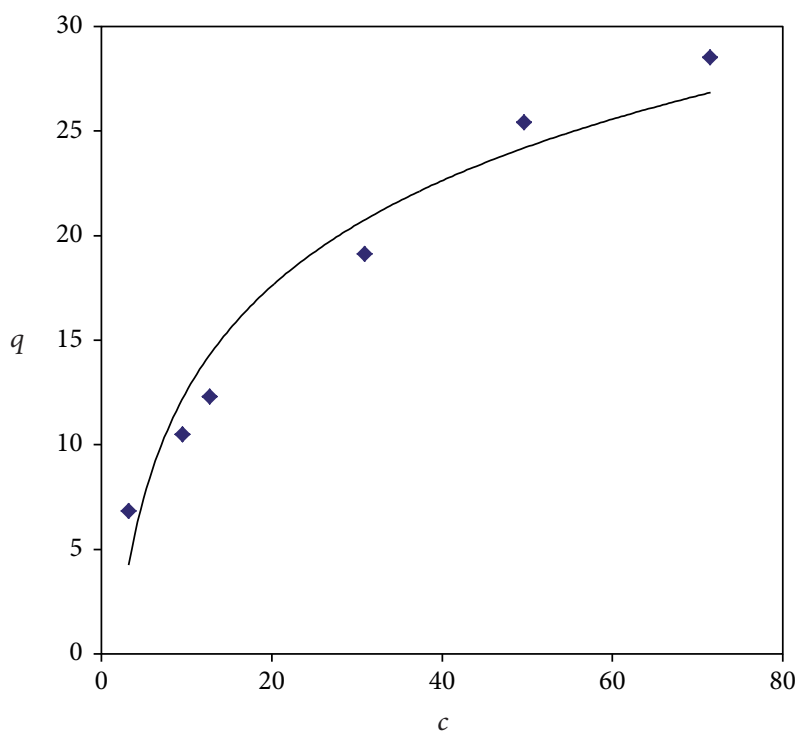

(a)

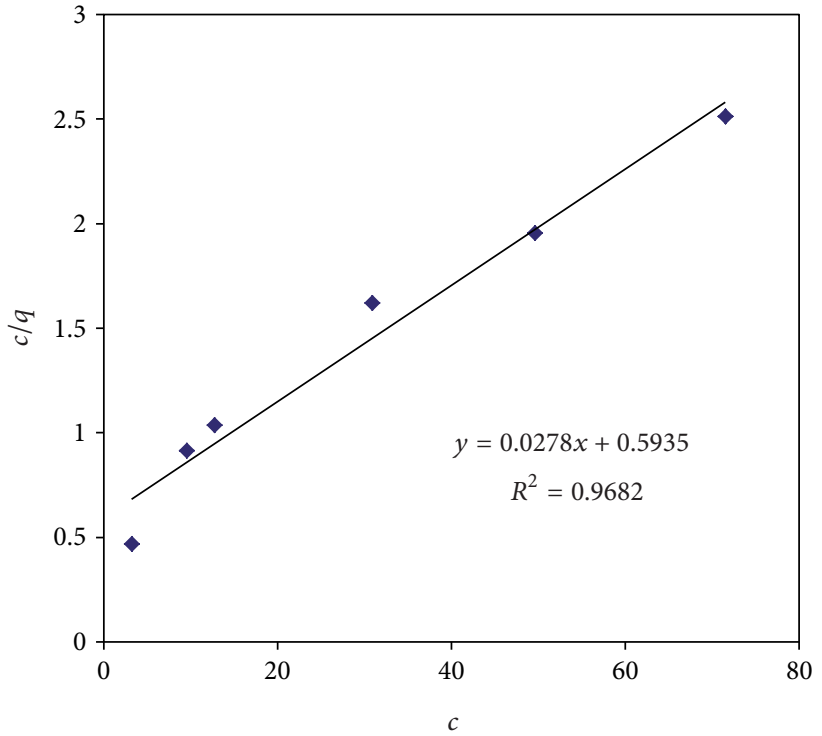

(b)

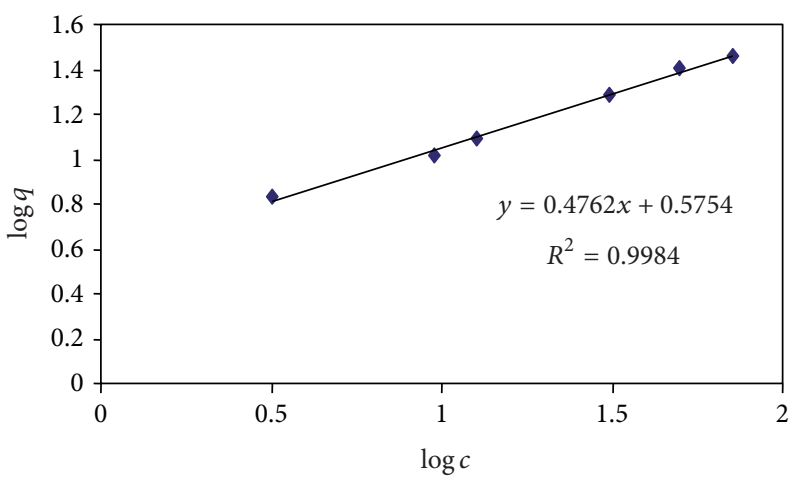

(c)

Figure 8: Plot of (a) sorption isotherm of Th(IV), (b) linearized Langmuir (III), and (c) linearized Freundlich at $\mathrm{pH}=1.0$ and $45^{\circ} \mathrm{C}$.

\section{Column Experiments}

4.1. Metal Ion Uptake by Bentonite. The investigation of metal ion uptake by bentonite using column experiments for thorium(IV) and uranium(VI) was determined at the optimum $\mathrm{pH}$ for each metal ion with initial concentration of $2000 \mathrm{ppm}$ at $25^{\circ} \mathrm{C}$ and flow rate of $1 \mathrm{~mL} / 2 \mathrm{~min}$. The results are expressed as percent metal uptake by the column and are presented in Table 10.

It can be seen that the uptake capacities of the metal ions fall in the order Th(IV) $>\mathrm{U}(\mathrm{VI})$.

It is observed that the \% uptake in column experiment is smaller than those obtained in batch experiment, because in order to achieve complete saturation, long time of contact is required. On the other hand, the shaking process in batch technique is a fundamental factor in addition to the large contact time, which increases the \% uptake of metal ions compared to column technique.

4.2. Desorption Studies. The main aim of this study is to determine the capability of bentonite to be regenerated for further uses. $50 \mathrm{~mL}$ of $1.0 \mathrm{M} \mathrm{HNO}_{3}, 0.5 \mathrm{M} \mathrm{HNO}_{3}, 0.1 \mathrm{M}$ $\mathrm{HNO}_{3}$, and $0.01 \mathrm{M} \mathrm{HNO}_{3}$ were used for the removal of metal ions and regeneration of bentonite, keeping flow rate of elution $1 \mathrm{~mL} / 2 \mathrm{~min}$. The elute was collected in ten portions, $5 \mathrm{~mL}$ for each portion; the results are expressed as percent recovery and represented in Table 11.

Depending on the values of percentage of cumulative recovery, in Table 11, the following trends were observed for eluting agents of Th(IV) and U(VI) from bentonite:

$$
\begin{aligned}
1.0 \mathrm{M} \mathrm{HNO}_{3} & >0.5 \mathrm{M} \mathrm{HNO}_{3} \\
& >0.1 \mathrm{M} \mathrm{HNO}_{3}>0.01 \mathrm{M} \mathrm{HNO}_{3}
\end{aligned}
$$

Table 11 shows desorption yields of uranium and thorium after ten desorption stages. Desorption yield for bentonite decreased with increasing the desorption stages. Thorium recovery decreases with decreasing acidity. When concentration of $\mathrm{HNO}_{3}$ is increased, desorption of uranium(VI) and thorium(IV) is increased due to cation exchange mechanism. It is clearly observed that the efficiency of Jordanian bentonite to adsorb metal ions for the second time is expected to 


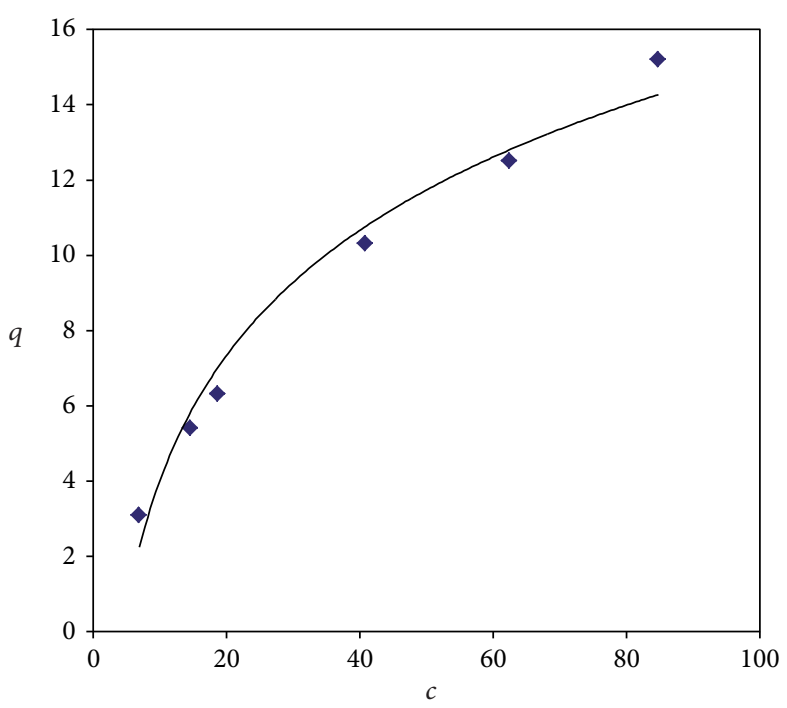

(a)

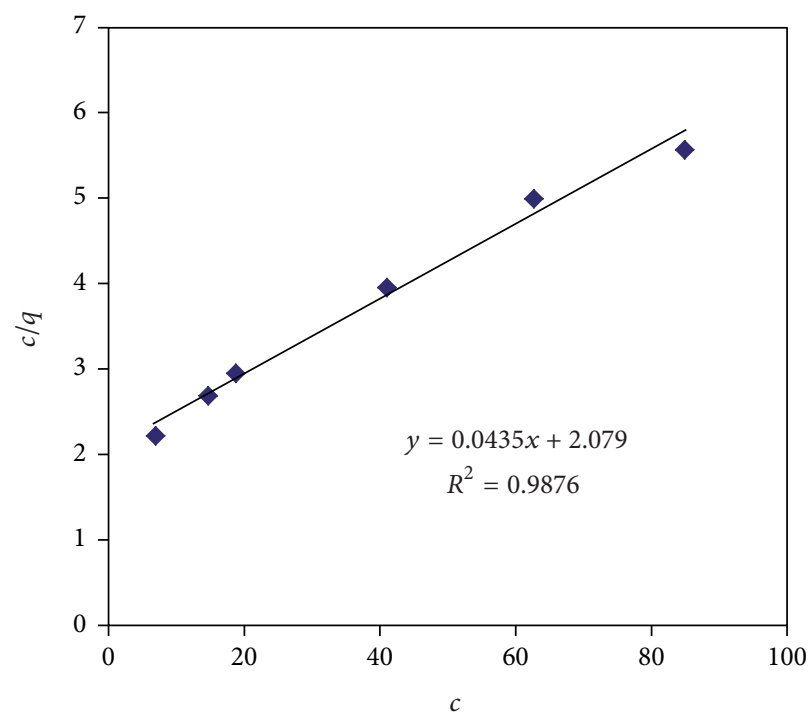

(b)

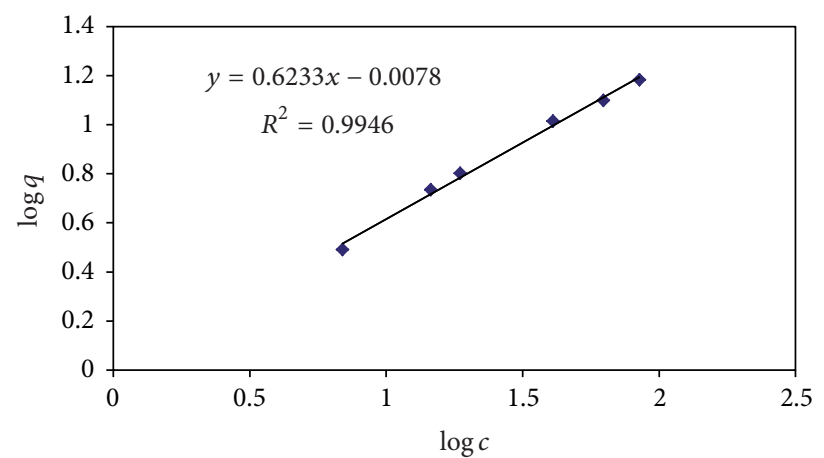

(c)

FIgURE 9: Plot of (a) sorption isotherm of U(VI), (b) linearized Langmuir (III), and (c) linearized Freundlich at $\mathrm{pH}=1$ and $25^{\circ} \mathrm{C}$.

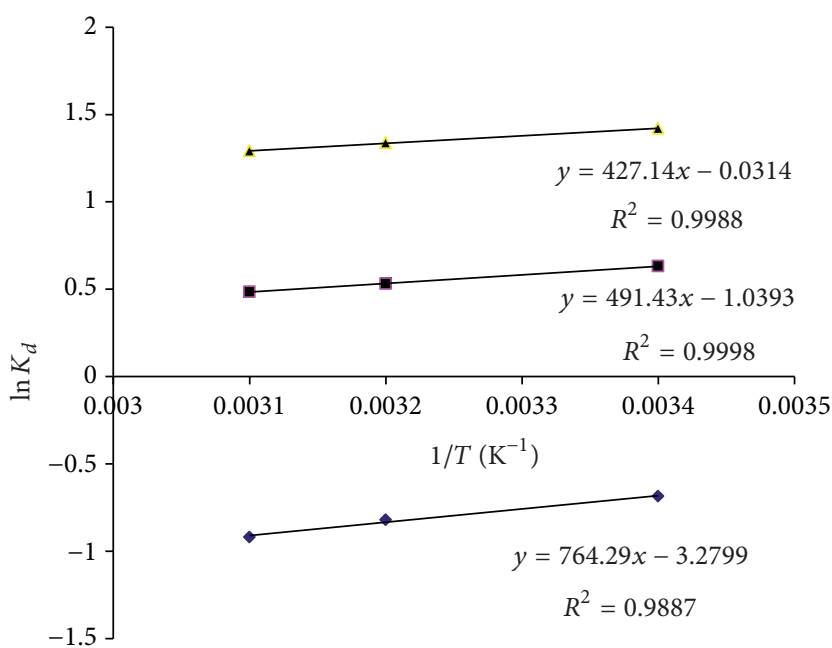

- $\mathrm{pH}=1$

- $\mathrm{pH}=2$

A $\mathrm{pH}=3$

FIgure 10: Plots of $\ln K_{d}$ versus $1 / T$ for Thorium (IV) at $\mathrm{pH}=1.0$, $\mathrm{pH}=2.0$, and $\mathrm{pH}=3.0$.

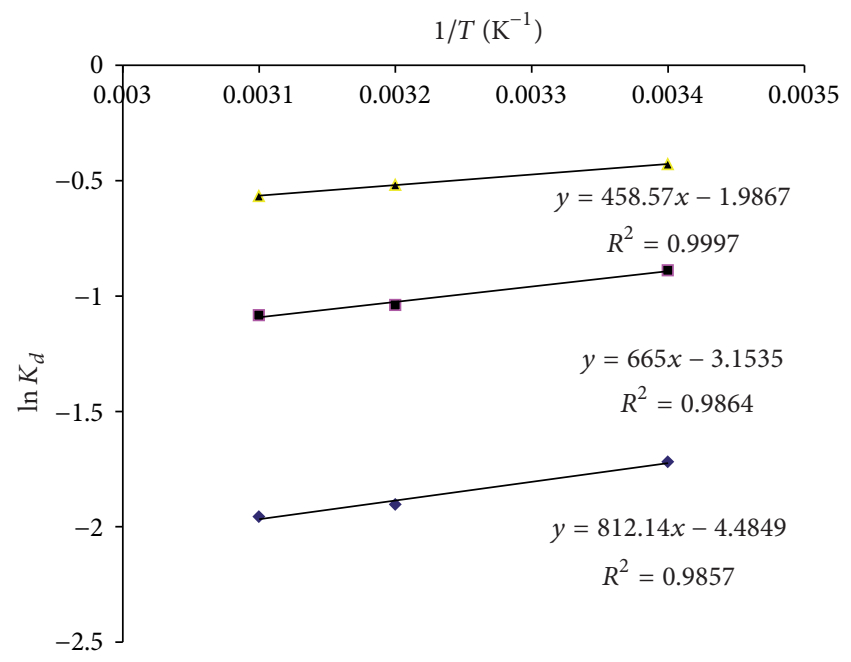

- $\mathrm{pH}=1$

- $\mathrm{pH}=2$

4. $\mathrm{pH}=3$

FIgURE 11: Plots of $\ln K_{d}$ versus $1 / T$ for Uranium(VI) at $\mathrm{pH}=1.0$, $\mathrm{pH}=2.0$, and $\mathrm{pH}=3.0$. 
TABLE 11: Desorption of U(VI) and Th(IV) ions from bentonite.

\begin{tabular}{|c|c|c|c|c|c|c|c|c|}
\hline \multirow{4}{*}{$\%$ Recovery } & \multicolumn{8}{|c|}{ Eluting agent } \\
\hline & \multirow{3}{*}{\multicolumn{2}{|c|}{$\begin{array}{c}1.0 \mathrm{M} \\
\mathrm{HNO}_{3} \\
\mathrm{U}(\mathrm{VI}) / \mathrm{Th}(\mathrm{IV})\end{array}$}} & \multirow{3}{*}{\multicolumn{2}{|c|}{$\begin{array}{c}0.5 \mathrm{M} \\
\mathrm{HNO}_{3} \\
\mathrm{U}(\mathrm{VI}) / \mathrm{Th}(\mathrm{IV})\end{array}$}} & \multirow{3}{*}{\multicolumn{2}{|c|}{$\begin{array}{c}0.1 \mathrm{M} \\
\mathrm{HNO}_{3} \\
\mathrm{U}(\mathrm{VI}) / \mathrm{Th}(\mathrm{IV})\end{array}$}} & \multirow{3}{*}{\multicolumn{2}{|c|}{$\begin{array}{c}0.01 \mathrm{M} \\
\mathrm{HNO}_{3} \\
\mathrm{U}(\mathrm{VI}) / \mathrm{Th}(\mathrm{IV})\end{array}$}} \\
\hline & & & & & & & & \\
\hline & & & & & & & & \\
\hline First portion & 4.793 & 12.651 & 3.925 & 9.072 & 3.141 & 7.180 & 2.439 & 10.257 \\
\hline Second portion & 4.410 & 9.156 & 3.801 & 9.010 & 2.781 & 6.743 & 2.227 & 9.837 \\
\hline Third portion & 4.406 & 9.125 & 3.208 & 8.789 & 2.675 & 6.403 & 2.215 & 6.282 \\
\hline Fourth portion & 3.856 & 7.524 & 3.164 & 8.589 & 2.675 & 6.055 & 2.162 & 5.316 \\
\hline Fifth portion & 3.845 & 6.527 & 2.661 & 8.544 & 2.663 & 4.819 & 2.161 & 2.283 \\
\hline Sixth portion & 3.836 & 6.251 & 2.573 & 4.636 & 2.663 & 4.484 & 1.623 & 2.277 \\
\hline Seventh portion & 3.695 & 6.141 & 2.549 & 3.430 & 2.593 & 3.878 & 1.576 & 2.272 \\
\hline Eighth portion & 3.559 & 5.872 & 1.996 & 3.353 & 2.546 & 3.464 & 1.270 & 2.219 \\
\hline Ninth portion & 3.535 & 5.861 & 1.994 & 2.638 & 1.993 & 2.645 & 0.853 & 2.005 \\
\hline Tenth Portion & 2.971 & 5.827 & 1.773 & 2.007 & 1.748 & 2.557 & 0.829 & 1.950 \\
\hline$\%$ Cumulative recovery & 38.905 & 69.109 & 27.594 & 60.069 & 25.479 & 48.227 & 17.354 & 44.699 \\
\hline
\end{tabular}

decrease significantly when desorption of the first time is done; this fact indicated that the washing of bentonite with $\mathrm{HNO}_{3}$ regenerates bentonite but the regeneration is not complete, since bentonite loses significant efficiency to adsorb metal ions for the second sorption process.

There are other studies showing the effectiveness of bentonite sorption of heavy metals from aqueous solution Table 12; the heavy metals which have been studied are $\mathrm{Pb}$ (II), $\mathrm{Cr}(\mathrm{III}), \mathrm{Zn}(\mathrm{II})$, and $\mathrm{Mn}$ (II). The sorption of these heavy metals on purified bentonite was studied as a function of contact time, $\mathrm{pH}$, temperature, and concentration variation [31]. The estimated parameters, $q_{m}$ and $K_{L}$, of the sorption isotherms for the three forms of linearized Langmuir equations were calculated from the intercept and slopes of the corresponding linear plots for $\mathrm{Zn}(\mathrm{II}), \mathrm{Pb}(\mathrm{II}), \mathrm{Cr}(\mathrm{III})$, and $\mathrm{Mn}$ (II) sorption onto bentonite at different temperatures and $\mathrm{pH}$ values. The values of these parameters for Langmuir Model form (II) with their correlation coefficients $\left(R^{2}\right)$ at $140 \mathrm{ppm}$ are given in Table 12.

From the following Tables 5, 6, and 12, it is clear that the sorption capacity of thorium and uranium in bentonite is slightly greater than the capacity of bentonite to sorb heavy metals except for $\mathrm{Pb}$ (II).

Accordingly, $q_{m}$ values for $\mathrm{Th}(\mathrm{IV})$ and $\mathrm{U}(\mathrm{VI})$ at $\mathrm{pH}=3.0$ as well as $\mathrm{Pb}(\mathrm{II}), \mathrm{Zn}(\mathrm{II}), \mathrm{Cr}(\mathrm{III})$, and $\mathrm{Mn}(\mathrm{II})$ at $\mathrm{pH}=4.0$ are decreasing generally in the following order:

$$
\mathrm{Th}(\mathrm{IV})>\mathrm{Pb}(\mathrm{II})>\mathrm{U}(\mathrm{VI})>\mathrm{Cr}(\mathrm{III})>\mathrm{Zn}(\mathrm{II})>\mathrm{Mn}(\mathrm{II})
$$

\section{Conclusion and Recommendations}

The present work has focused on the purification of Jordanian bentonite and then studying its sorption characteristics toward Th(IV) and U(VI). Raw and purified bentonites were characterized by XRD, XRF, and SEM. The sorption characteristics for Th(IV) and U(VI) ions from aqueous solutions were examined under various experimental conditions using both batch and column techniques. The effective desorption
TABLE $12: R^{2}$, and $q_{m}, K_{L}$ values obtained for heavy metals from Langmuir form (II) plots.

\begin{tabular}{lccc}
\hline $\mathrm{M}(\mathrm{II})$ & & & \\
$T=25^{\circ} \mathrm{C}$ & $K_{L}(\mathrm{~L} / \mathrm{mg})$ & $q_{m}(\mathrm{mg} / \mathrm{g})$ & $R^{2}$ \\
$\mathrm{pH}=4.0$ & & 9.05 & 0.9991 \\
$\mathrm{Zn}(\mathrm{II})$ & 1.2657 & 76.34 & 0.9994 \\
$\mathrm{~Pb}(\mathrm{II})$ & 0.0912 & 37.31 & 0.9997 \\
$\mathrm{Cr}(\mathrm{III})$ & 1.0114 & 6.05 & 0.9966 \\
$\mathrm{Mn}(\mathrm{II})$ & 0.4837 & & \\
\hline
\end{tabular}

of the metal ions was also studied and the coefficients of recovery of sorption ability were also investigated.

The following remarks are concluded.

(1) Jordanian bentonite showed a relatively high uptake for thorium(IV) and lower uptake for uranium(VI).

(2) The influence of different $\mathrm{pH}$ on metals uptake showed that the metal ion uptake by bentonite increased with $\mathrm{pH}$ and reached a maximum at $\mathrm{pH}=3$ for $\mathrm{Th}^{4+}$ and $\mathrm{UO}_{2}{ }^{2+}$.

(3) The maximum sorption capacity $\left(q_{m}\right)$ of bentonite was high for $\mathrm{Th}^{4+}$ and the extent of metal ions uptake followed the order: $\mathrm{Th}^{4+}>\mathrm{UO}_{2}{ }^{2+}$ at $\mathrm{pH}=3$ and $25^{\circ} \mathrm{C}$.

(4) The equilibrium for each metal ion on the surface of bentonite occurs at 18 hours to achieve maximum uptake level.

(5) The adsorptive process is enthalpy driven for uranium(VI) and thorium(IV).

(6) A glass column was packed with bentonite and exhibits good sorption properties toward metal ions. The regeneration process of bentonite was done using different concentration of $\mathrm{HNO}_{3}$ and the results show that this process is effective for environmental applications. 
(7) The best percent recovery for thorium(IV) and uranium(VI) was obtained when $1.0 \mathrm{M} \mathrm{HNO}_{3}$ was used.

(8) Thorium (IV) and uranium (VI) removal with bentonite is well described by the second-order reaction kinetic.

(9) This study strongly recommends the use of Jordanian bentonite to remove radioactive wastes; such wastes arise from technologies producing uranium and from laboratories working with radioactive materials.

\section{References}

[1] D. Sun, H. Cui, and W. Sun, "Swelling of compacted sandbentonite mixtures," Applied Clay Science, vol. 43, no. 3-4, pp. 485-492, 2009.

[2] L. H. Mollins, D. I. Stewart, and T. W. Cousens, "Predicting the properties of bentonite-sand mixtures," Clay Minerals, vol. 31, no. 2, pp. 243-252, 1996.

[3] P. Misaelides, A. Godelitsas, A. Filippidis, D. Charistos, and I. Anousis, "Thorium and uranium uptake by natural zeolitic materials," Science of the Total Environment, vol. 173-174, pp. 237-246, 1995.

[4] H. Khoury, Industrial Rocks and Minerals in Jordan, University of Jordan, Amman, Jordan, 2nd edition, 2006.

[5] A. Tsunashima, G. W. Brindley, and M. Bastovanov, "Adsorption of uranium from solutions by montmorillonite; compositions and properties of uranyl montmorillonites," Clays \& Clay Minerals, vol. 29, no. 1, pp. 10-16, 1981.

[6] J. P. McKinley, J. M. Zachara, S. C. Smith, and G. D. Turner, "The influence of uranyl hydrolysis and multiple site-binding reactions on adsorption of U(VI) to montmorillonite," Clays \& Clay Minerals, vol. 43, no. 5, pp. 586-598, 1995.

[7] R. T. Pabalan and D. R. Turner, "Uranium(6+) sorption on montmorillonite: experimental and surface complexation modeling study," Aquatic Geochemistry, vol. 2, no. 3, pp. 203-226, 1996.

[8] D. M. Giaquinta, L. Soderholm, S. E. Yuchs, and S. R. Wasserman, "Hydrolysis of uranium and thorium in surface-modified bentonite under hydrothermal conditions," Journal of Alloys and Compounds, vol. 249, no. 1, pp. 142-145, 1997.

[9] R. Donat and S. Aytas, "Adsorption and thermodynamic behavior of uranium(VI) on Ulva sp.-Na bentonite composite adsorbent," Journal of Radioanalytical and Nuclear Chemistry, vol. 265, no. 1, pp. 107-114, 2005.

[10] J. G. Catalano and G. E. Brown, "Uranyl adsorption onto montmorillonite: evaluation of binding sites and carbonate complexation," Geochimica et Cosmochimica Acta, vol. 69, no. 12, pp. 2995-3005, 2005.

[11] D. L. Zhao, S. J. Feng, C. L. Chen, S. H. Chen, D. Xu, and X. K. Wang, "Adsorption of thorium(IV) on MX-80 bentonite: effect of $\mathrm{pH}$, ionic strength and temperature," Applied Clay Science, vol. 41, no. 1-2, pp. 17-23, 2008.

[12] J. S. Al-Jariri and F. Khalili, "Adsorption of $\mathrm{Zn}(\mathrm{II}), \mathrm{Pb}(\mathrm{II})$, $\mathrm{Cr}(\mathrm{III})$ and $\mathrm{Mn}(\mathrm{II})$ from water by Jordanian bentonite," Desalination and Water Treatment, vol. 21, no. 1-3, pp. 308-322, 2010.

[13] M. Al-Shaybe and F. Khalili, "Adsorption of thorium (IV) and uranium (VI) by tulul al- shabba zeolitic tuff, Jordan," Jordan Journal of Earth and Environmental Sciences, vol. 2, no. 1, pp. 108-109, 2009.
[14] M. Salman, B. El-Eswed, and F. Khalili, "Adsorption of humic acid on bentonite," Applied Clay Science, vol. 38, no. 1-2, pp. 51-56, 2007.

[15] S. B. Savvin, "Analytical use of arsenazo III. Determination of thorium, zirconium, uranium and rare earth elements," Talanta, vol. 8, no. 9, pp. 673-685, 1961.

[16] F. Khalili, S. A. Al-Taweel, Y. Y. Yousef, and S. A. Al-Tarawneh, "Synthesiss characterization and solvent extrachion properties of new Thiophene based trifluoromethyl-substituted Bdiketones for Thorium(IV) and uranium(VI) Ions," Journal of Saudi Chemical Society, vol. 12, no. 2, pp. 165-176, 2008.

[17] W. K. Mekhemera, J. A. Hefneb, N. M. Alandisa, O. A. Aldayel, and S. Al-Raddadi, "Thermodynamics and kinetics of Co (II) adsorption onto natural and treated bentonite," Jordan Journal of Chemistry, vol. 3, no. 4, pp. 409-423, 2008.

[18] D. M. Manohar, B. F. Noeline, and T. S. Anirudhan, "Adsorption performance of Al-pillared bentonite clay for the removal of cobalt(II) from aqueous phase," Applied Clay Science, vol. 31, no. 3-4, pp. 194-206, 2006.

[19] A. Tabak, B. Afsin, B. Caglar, and E. Koksal, "Characterization and pillaring of a Turkish bentonite (Resadiye)," Journal of Colloid and Interface Science, vol. 313, no. 1, pp. 5-11, 2007.

[20] National Resources Authority, Bentonite, National Resources Authority, Amman, Jordan, 2006.

[21] S. Veli and B. Alyüz, "Adsorption of copper and zinc from aqueous solutions by using natural clay," Journal of Hazardous Materials, vol. 149, no. 1, pp. 226-233, 2007.

[22] C. Paduraru, D. Bilba, I. Sarghie, and L. Tofan, "A sorption study of $\mathrm{Pd}(\mathrm{II})$ on aminomethylphosphonic purolite resin S940," Journal of the Serbian Chemical Society, vol. 70, no. 10, pp. 1205-1212, 2005.

[23] G. Mckay and F. Porter, "Equilibrium parameters for the sorption of copper, cadmium and zinc ions onto peat," Journal of Chemical Technology \& Biotechnology, vol. 69, pp. 309-320, 1997.

[24] S. J. Allen, G. McKay, and K. Y. H. Khader, "Multi-component sorption isotherms of basic dyes onto peat," Environmental Pollution, vol. 52, no. 1, pp. 39-53, 1988.

[25] W. Helbig, "Adsorption liquid phase processes are important," Journal of Chemical Engineering, vol. 59, pp. 153-158, 1952.

[26] J. P. Hunt, Metal Ions in Aqueous Solutions, Benjamin Inc., New York, NY, USA, 2nd edition, 1965.

[27] S. P. Sinha, Complexes of the Rare Earths, Pergamon Press, London, UK, 1st edition, 1966.

[28] R. Donat, A. Akdogan, E. Erdem, and H. Cetisli, "Thermodynamics of $\mathrm{Pb}^{2+}$ and $\mathrm{Ni}^{2+}$ adsorption onto natural bentonite from aqueous solutions," Journal of Colloid and Interface Science, vol. 286, no. 1, pp. 43-52, 2005.

[29] D. Xu, X. L. Tan, C. L. Chen, and X. K. Wang, "Adsorption of $\mathrm{Pb}$ (II) from aqueous solution to MX-80 bentonite: effect of $\mathrm{pH}$, ionic strength, foreign ions and temperature," Applied Clay Science, vol. 41, no. 1-2, pp. 37-46, 2008.

[30] S. E. Fendorf and G. Li, "Kinetics of chromate reduction by ferrous iron," Environmental Science and Technology, vol. 30, no. 5, pp. 1614-1617, 1996.

[31] D. C. Lee, C. J. Park, J. E. Yang, Y. H. Jeong, and H. I. Rhee, "Screening of hexavalent chromium biosorbent from marine algae," Applied Microbiology and Biotechnology, vol. 54, no. 3, pp. 445-448, 2000. 

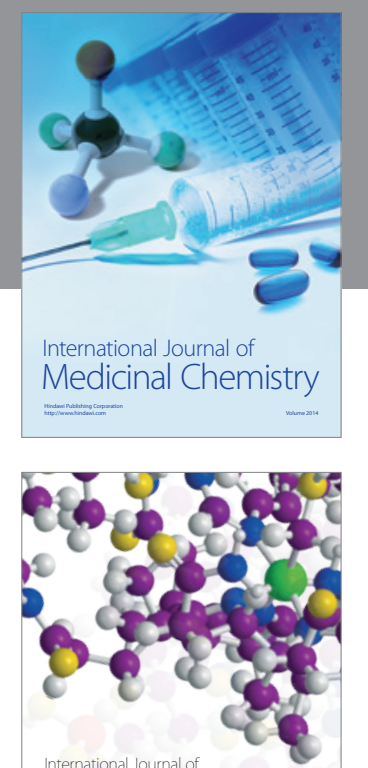

\section{Carbohydrate} Chemistry

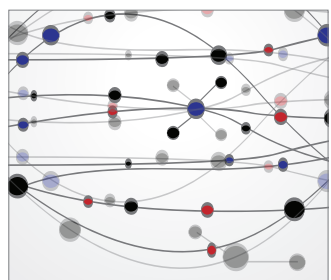

The Scientific World Journal
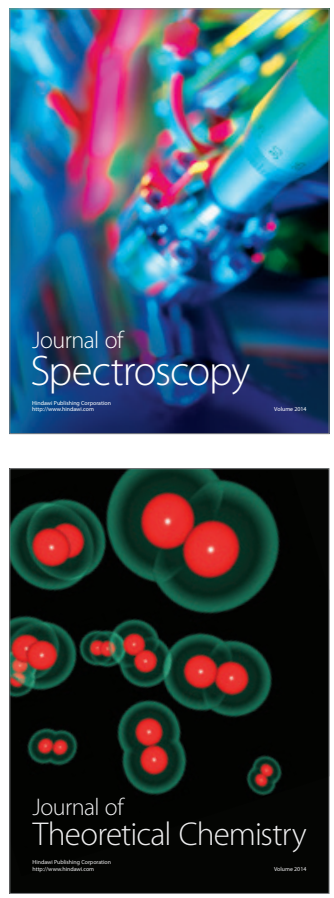
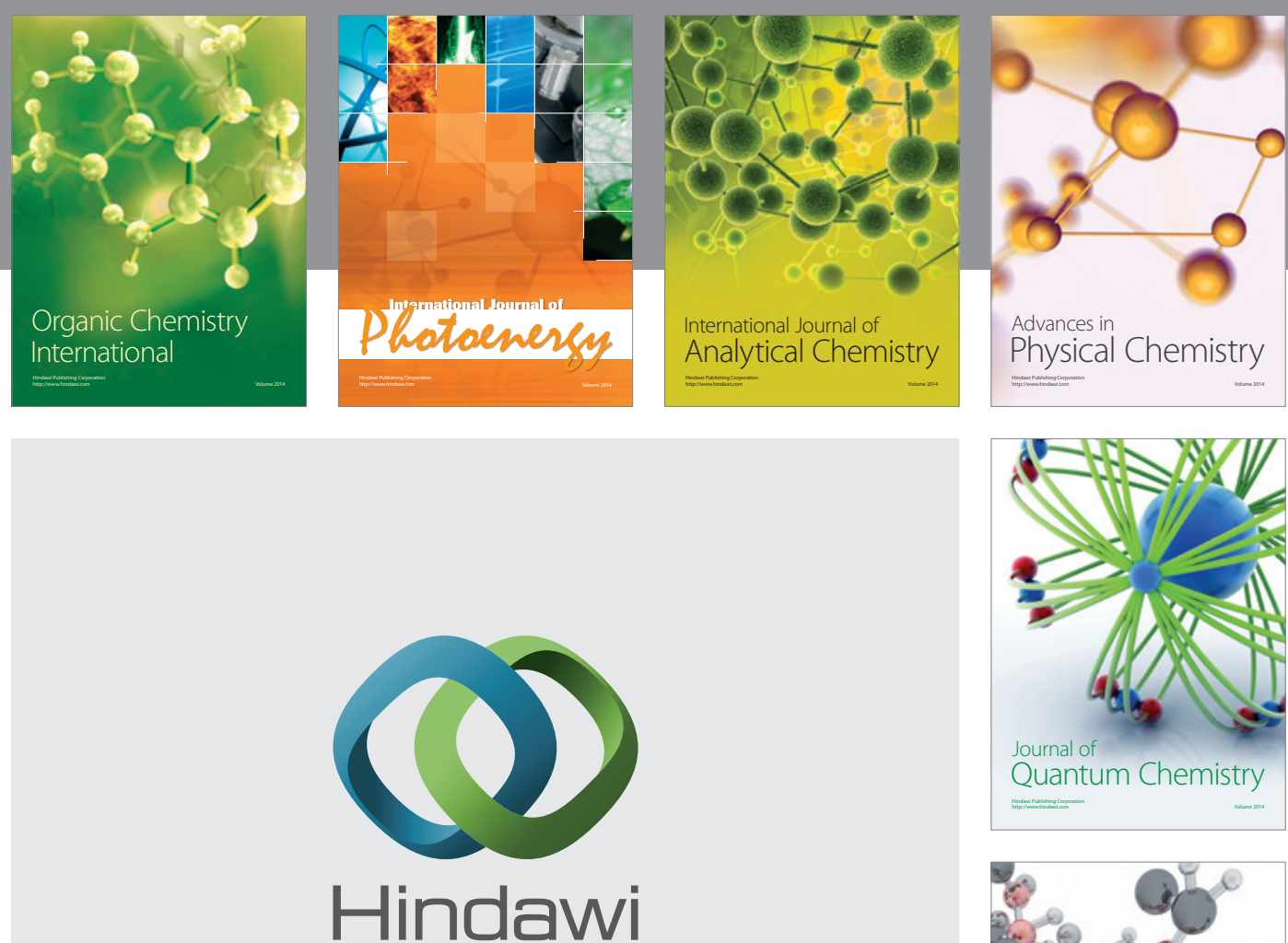

Submit your manuscripts at

http://www.hindawi.com

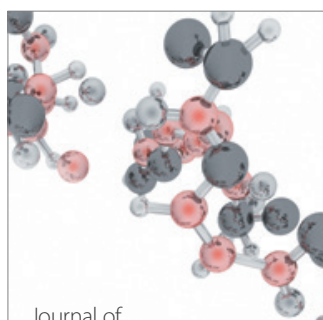

Analytical Methods

in Chemistry

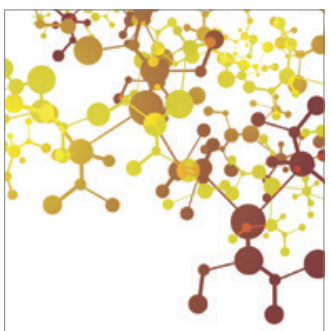

Journal of

Applied Chemistry

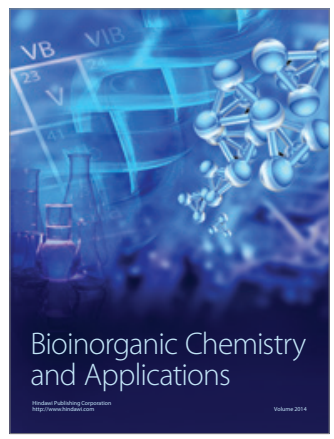

Inorganic Chemistry
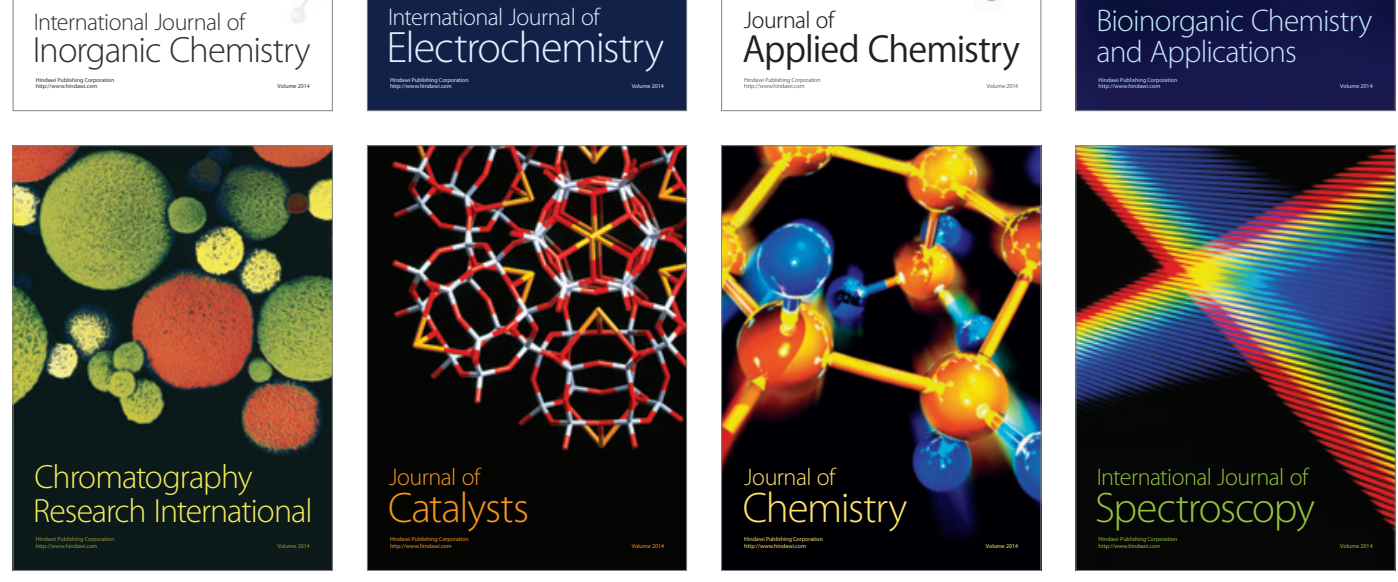